\title{
Editorial
}

\section{Is the demographic of British Journal of Nutrition authors changing?}

In 2006, I published an Editorial in part describing the geographical origin of papers published in the British Journal of Nutrition $(B J N)$ during $2005^{(1)}$. I noted that, based upon the address of the corresponding author, $67.4 \%$ of published papers originated from Europe (21.6\% from the UK), $17 \%$ from Asia, $8.9 \%$ from North America, $4.3 \%$ from Australasia, $1.8 \%$ from Latin America and $0.7 \%$ from Africa. I have now repeated this exercise for papers published in the $B J N$ during 2009. The results are shown in Table 1. Comparing these latest figures with those from just 4 years ago highlights some interesting trends. Whilst Europe remains the region of origin of the majority of published papers, the contribution of this region has fallen by about $10 \%$, with a fall in the relative number of papers of UK origin of almost $39 \%$ from $21.6 \%$ to $13.2 \%$ of all published papers. In contrast, the relative contribution of papers of North American origin has increased by almost $70 \%$, while that of those of Latin American or Australasian origin has increased by almost $90 \%$ and by over $85 \%$, respectively. The relative contribution of papers of Asian origin has decreased by almost $40 \%$. It is important to note that the total number of papers published in the $B J N$ has gone up considerably over the last 4 years (from 282 to 500 ), so that the absolute number of papers published from all regions has increased (Table 2). The result of the increased number of papers published and the increased contribution of papers from North America, Latin America and Australasia means that, in absolute terms, 200, 240 and $233 \%$ more papers were published from those three regions, respectively, in 2009 compared with 2005. The absolute increase in the number of papers of European and Asian origin was 58 and $27 \%$, respectively. The changing pattern in the geographical origin of published papers perhaps reflects the large increase in submissions of manuscripts from North America, Latin America and Australasia.

It appears that even within regions there is a greater diversity of the origin of papers published in the BJN. In 2009, papers were published from twenty European countries other than the UK (sixteen in 2005), corresponding to over $45 \%$ of total publications, with Spain (9.8\% of papers), France ( $7.0 \%$ of papers), Germany ( $6.0 \%$ of papers), The Netherlands (6.6\% of papers) and Finland (4.0\% of papers) being prominent. Scandinavian countries contributed $5 \%$ of published papers. Papers were published from both the USA ( $9.0 \%$ of papers) and Canada (6.0\% of papers), from five Latin American countries (two in 2005), six Asian countries (Japan (4.8\% of papers), People's Republic of China, Republic of China (i.e. Taiwan), South Korea, India and Malaysia), Australia (6.2\% of papers), New Zealand, South Africa, Egypt, Israel and Lebanon. In total, papers from forty countries were published in the $B J N$ during 2009 (thirty countries in 2005). These figures demonstrate the remarkable geographical diversity of the papers published in the $B J N$ and, I think, demonstrate the true international nature of the $B J N$.

The international nature of the $B J N$ is also reflected amongst those who participate in the peer review and decision-making processes. Of the four Deputy Editors of the $B J N$, one is French, one Canadian and one American. The Editorial Board includes members from sixteen countries. Only $32 \%$ of the Editorial Board is British (40\% in 2005); there are twenty-one members from eight countries in Continental Europe, fifteen North American members, and members from South Korea, Iran, Australia and New Zealand. Manuscript reviewers cover an even wider geographical spread.

Table 1. Regions of affiliation of corresponding authors of articles published in the British Journal of Nutrition during 2009

\begin{tabular}{|c|c|c|c|c|c|c|c|c|}
\hline \multirow[b]{2}{*}{ Region } & \multicolumn{2}{|c|}{$\begin{array}{l}\text { Full papers and Short } \\
\text { communications }\end{array}$} & \multicolumn{2}{|c|}{$\begin{array}{l}\text { Other articles published in } \\
\text { main issues }\end{array}$} & \multicolumn{2}{|c|}{$\begin{array}{l}\text { Articles published in } \\
\text { Supplements }\end{array}$} & \multicolumn{2}{|c|}{ Total } \\
\hline & $n$ & $\%$ & $n$ & $\%$ & $n$ & $\%$ & $n$ & $\%$ \\
\hline Europe (of which UK) & $250(58)$ & $57 \cdot 3(13 \cdot 3)$ & $31(7)$ & $70.5(15.9)$ & $20(1)$ & $100(5 \cdot 0)$ & $301(66)$ & $60 \cdot 2(13 \cdot 2)$ \\
\hline North America & 65 & 14.9 & 10 & $22 \cdot 7$ & - & - & 75 & $15 \cdot 0$ \\
\hline Latin America & 17 & 3.9 & - & - & - & - & 17 & 3.4 \\
\hline Africa & 3 & 0.7 & 1 & $2 \cdot 3$ & - & - & 4 & 0.8 \\
\hline Asia & 60 & $13 \cdot 8$ & 1 & $2 \cdot 3$ & - & - & 61 & $12 \cdot 2$ \\
\hline Middle East & 2 & 0.5 & - & - & - & - & 2 & 0.4 \\
\hline Australasia & 8 & 3.5 & 1 & $2 \cdot 3$ & - & - & 40 & 8.0 \\
\hline
\end{tabular}

*Includes Invited Commentaries, Review articles, Systematic reviews, Meta-analyses and Letters to the Editor. 
Table 2. Regions of affiliation of corresponding authors of articles published in the British Journal of Nutrition during 2005 and 2009

\begin{tabular}{|c|c|c|c|c|}
\hline \multirow[b]{2}{*}{ Region } & \multicolumn{2}{|c|}{2005} & \multicolumn{2}{|c|}{2009} \\
\hline & $n$ & $\%$ & $n$ & $\%$ \\
\hline $\begin{array}{l}\text { Europe } \\
\text { (of which UK) }\end{array}$ & $190(61)$ & $67.4(21.6)$ & $301(66)$ & $60 \cdot 2(13 \cdot 2)$ \\
\hline North America & 25 & 8.9 & 75 & $15 \cdot 0$ \\
\hline Latin America & 5 & 1.8 & 17 & 3.4 \\
\hline Africa & 2 & 0.7 & 4 & $0 \cdot 8$ \\
\hline Asia & 48 & $17 \cdot 0$ & 61 & $12 \cdot 2$ \\
\hline Middle East & - & - & 2 & 0.64 \\
\hline Australasia & 12 & 4.3 & 40 & 8.0 \\
\hline
\end{tabular}

Thus, there is plenty of evidence that those responsible for reviewing and making decisions on manuscripts submitted to the $B J N$ represent a very international mix. It is my view that this mix reflects that of the authorship and readership of the $B J N$, and that the $B J N$ is truly an international, not only a British, journal.

Philip C. Calder

Editor-in-Chief Institute of Human Nutrition

School of Medicine University of Southampton Southampton $U K$ email pcc@soton.ac.uk doi:10.1017/S0007114510001959

\section{Reference}

1. Calder PC (2006) The British Journal of Nutrition, an international journal that continues to develop. Br J Nutr 96, 1-3. 